telecommunication, electrical engineering, electronics, mechanics of continuous modia, fluid mochanics, vibrations research and analogues, and a laboratory for research on isotopes.

\section{Radioisotopes and Radiation in Entomology}

The International Atomic Energy Agency in Vienna recently convened a symposium under the above title with the object of discussing and developing plans for the wider use of radioisotopes and radiation in the control of insect pests. It was held in Bombay during December 5-9, 1960, when twenty. five papers were read and discussed by delegates from the host country, India, Federal Republic of Germany, France, Italy, Pakistan, Philippines, United Kingdom, United States and U.S.S.R. The papers covered a pertinent range of topics, such as the use of irradiation as a direct means of disinfesting food products, as an indirect means by inducing sterility in male insects, and so interrupting reproduction in field populations, and the use of radioactive tracers in entomological and insect biochemical research. There was lively but constructive discussion, for example, in the respective merits of static radioactive materials and electrical machines as radiation sources. Through the kindness of the Indian Government the delegates visited the Atomic Energy Establishment and the new reactor at Trombay, where impressive facilities have been created for the peaceful applications of atomic energy. There are major agricultural and insect pest problems in the less-developed regions of the world in which irradiation and radioisotope techniques can undoubtedly play a valuable part. Excellent facilities for the application of these techniques now exist in India, so that the symposium was indeed timely and effective. The balaneed and upto-date nature of the programme will render the collected proceedings a valuable document provided that publication is not long delayed.

\section{Sabouraudia}

The aptly named Sabouraudia, the new journal of the recently formed International Society for Human and Animal Mycology and the first number of which was published during January, can truly be regarded as a milestone marking the rapid extension of the science of mycology into the sphere of human and animal mycoses (Vol. 1, Part 1. Edited by J. C. Gentles. Pp. $72+12$ plates. (Edinburgh and London: E. and S. Livingstone, Ltd., 1961). Subscription price per volume (four issues) $80 s$. or 12 dollars. Single parts $20 s$. or 3 dollars). Indeed, as pointed out in an excellent review of the subject by the president, Dr. Juan Makinnon, order is steadily being brought out of chaos by the insistence of a few discerning enthusiasts on the observance of the rules of the international codes of nomenclature for bacteriology and botany. It is, perhaps, the recent trend towards accuracy in species diagnosis and nomenclature of the causal fungi, in contrast to the over-emphasis on clinical aspects characteristic of older work, which has been responsible for the enhanced status of medical and veterinary mycology. This is well exemplified by two papers describing some of the techniques being evolved for obtaining the sexual, or 'perfect', states of parasites content to be known previously only by their conidial states. The remaining six papers are of an agreeably high standard, and mycology will be well served if the journal continues to main- tain this standard. It is printed clearly on good quality, quarto-sized paper with excellently produced illustrations, and includes book and film reviews and news of scientific societies in a total of 71 pages.

\section{Protection of Cleaned Iron Objects}

THE protection of iron objects after they have been cleaned has for a long time been a major problem in the conservation of museum objects. In the February issue of the Museums Journal, Mr. K. J. Barton details some experiments and conclusions on this subject. The most interesting result is that the phosphate coated object (using one of the commercial phosphoric acid cleaners) shows no evidence of corrosion under the experiments. The one disadvantage of this coating is that the resultant colour is poor and always patchy. This can be overcome by dyeing the phosphate coating black with 'Hematine' crystals, thus giving matt surface which can be polished with a stiff brush. Other tests covered vapour-phase inhibitors using cyclohexylamine carbonate. Shell Nos. 220 and 260 were found to be the most effective and their use is limited to objects made of steel, iron, tinplate, zinc and aluminium. They must not be used in association with lead or copper since they are liable to attack.

\section{Atmosphere Temperature Fluctuations}

THE subject of climatic change is one which has for long interested climatologists and meteorologists, but especially so during recent years. Direct temperature observations, the recession of glaciers, the movement of fish and insects northwards in the northern hemisphere, as well as a similar movement of the tree-line have all indicated an appreciable rise in atmospheric temperature in many parts of the world during the past few decades. A recent contribution to the subject has been made by G. S. Callendar, of the Ministry of Aviation, in a paper which appears in the Quarterly Journal of the Royal Meteorological Society (87, No. 371 ; Jan. 1961). From his analysis he concludes that the rising trend is significant from the Arctic to about $45^{\circ} \mathrm{S}$. lat., but is small and indeed locally non-apparent in regions below $35^{\circ} \mathrm{N}$. as yet. A number of theories to account for the rise have been advanced, and there has been much speculation as to whether or for how long it will continue. One widely held theory is to the effect that the rising trend is a result of increased incoming solar radiation, due either to an increased output of solar energy or to an increased atmospheric transparency resulting from a decrease in volcanic activity. Callendar considers that such a hypothesis is not inconsistent with the observed zonal short-period fluctuations, but that it fails to explain the pattern of the overall climatic trend. The latter is considered to be not incompatible with the increased carbon dioxide theory, which is to the effect that the trend could be due to back radiation from the additional carbondioxide produced by fossil-fuel combustion. The points at issue seem to be: Does Nature control the whole process, or has human activity caused the trend, on which Nature has merely imposed the fluctuations?

\section{Corrosion Prevention}

A SPECIAL exhibition on metallic corrosion and its prevention is being organized at the Science Museum, South Kensington, during March 27April 22. This collection of exhibits has been 